\title{
REPRESENTATION OF COCA COLA AS AMERICAN MULTICULTURAL ICON IN THE TV ADVERTISEMENT AMERICA IS BEAUTIFUL
}

\author{
Benita Amalina \\ benita.amalina@gmail.com
}

\begin{abstract}
On February 2, 2014, Coca Cola released a new television advertisement titled "America is Beautiful" during Super Bowl event. The advertisement shows American multicultural families having a good time together. What makes this advertisement different from the previous ones, is the usage of a patriotic song America is Beautiful as the musical background. This research examines how Coca Cola as a brand represents the multicultural America through this advertisement. The result shows that it is affected by the historical values and the fact that the CEO of Coca Cola blatantly advertise multicultural America by encouraging and supporting the immigrants.
\end{abstract}

Keywords: Advertisement, popular culture, multiculturalism, immigrants

\section{INTRODUCTION}

Advertisement is one of the priority marketing strategy to promote certain products, as it has been an effective commodity to reach out to new consumers. In United States, the emergence of advertisement started out in the eighteenth century when the American people were still dependent to British consumer productsporcelain, furniture, musical instruments - in which it usually showed persuasive appeals accompanied with dry descriptions on a paper. ${ }^{1}$ After they gained independence and the economic power rised along with the evolving technology, the forms of advertisement also developed into many types of audio-visual. Audio visual communications, in terms of television broadcast advertisement is one of the most effective and powerful medium to spread and promote a product, and also to campaign something.

1 Daniel Pope, "Making Sense of Advertisements", History Matters: The U.S. Survey on the Web
Coca-Cola, as the biggest beverage company in the world from United States, has also been optimizing the use of advertisements to promote its product. With a handful of professionals in their marketing team, Coca-Cola made a significant change within their advertisement with not only promoting its product, but also delivering 'implied' message. Coca-Cola has been the most popular icon of soda beverages, and it has been producing numerous campaigns within their marketing strategy with 'catchy' slogans, including 'America's Real Choice', 'Open Happiness', or 'Life Begins Here'. As a commercial company, their main objective is to obtain profits as much as possible and such slogans are created to reach out broader market and possible new consumers. However, such campaigns did affect the society, as Coca-Cola has become the 'icon of togetherness' and it's prevalent to find the product on the table whenever a gathering occurred. Coca-Cola isn't merely a beverage product, it grew as a culture and a lifestyle, in which most people would buy and follow the trend created by the product without question. 
As the popularity of the product grows biggerwith international offices in more than 200 countries - Coca-Cola also transcends into not just a beverage product, but also an American icon. Earlier this year, Coca-Cola released a new television titled "America is Beautiful", which featured Americans with multi-ethnic figures. As previously being famous of creating advertisement that 'challenges racial boundaries', this time Coca-Cola seems to take it to a whole new level by showing that this product belongs to the country that celebrates people of the world. In another word, the product Coca-Cola here is seen as representing an 'American icon'. This paper examines about how Coca-Cola implies a lot of meanings within its newest television advertisement; especially the multicultural America.

\section{METHODOLOGY}

Representation is an essential part of the process by which meaning is produced and exchanged between members of culture (Hall, 1997, p. 15). One of the most common ways to represent certain concept is by describing or depicting it within a portrayal or imagination, which will be the main theme of this paper. The meaning that's fundamentally underlying the main concept carries certain value that is constructed by the producers or makers of the concept to be grasped by their targets of objects. The process is structurally explained by Saussure, in which he divided the language of representation into signifier and signified.

Signifier, the first element of the sign, refers to what we actually see-it's the actual product. This signifier will imply a certain concept or idea within our heads, which defines and gives meaning to it, called the signified. Although these might seem to be two separate entities, they exist only as components of the sign which is the central fact of language (Culler, 1976, p.
19). Saussure also argues that signs are "members of a system and are defined in relation to the other members of that system"for example, it is hard to define the meaning of 'father' except in relation to, and in terms of its difference from other kinship terms, like 'mother', 'daughter', 'son', and so on (Hall, 1997, p. 31). However, the relation between signifier and signified are arbitrary as it isn't permanently fixed and it can historically change. The change can be seen within an evolvement of certain culture, which has certain historical moment causing the culture to have different point of view compared to another. According to Saussure:

Language sets up an arbitrary relation between signifiers of its own choosing on the one hand, and signifieds of its own choosing on the other. Not only does each language produce a different set of signifiers, articulating and dividing the continuum of sound (or writing or drawing or photography) in a distinctive way; each language produces a different set of signifieds, it has a distinctive and thus arbitrary way of organizing the world into concepts and categories. (Culler, 1976, p. 23)

The change of the relation of signifier and signified makes it possible for audience (or viewer or reader) to interpret different meanings and not exactly what has been given by the producer. This is also included within the historical process of interpretation of a certain product, and this is where audience takes important part to prove that "signs which have not been intelligibly received and interpreted are not, in any useful sense, 'meaningful'" (Hall, 1997, p. 33). To communicate the certain meaning itself, Saussure divides language into two parts; the underlying rule-governed structure of language, which enables us to produce well-formed sentences, the langue; and 
particular acts of speaking or writing or drawing [...] produced by the actual speaker or drawer called the parole (Culler, 1976, p. 29). According to Saussure's structure schema, "each authored statement only becomes possible because the 'author' shares with other languageusers the common rules and codes of the language system - the langue - which allows them to communicate with each other meaningfully (Hall, 1997, p. 34).

For this paper, the signifier and the signified will be derived from the television advertisement "America is Beautiful", in which Coca-Cola, isn't merely a beverage product but also conveys another signified meaning or concept; an American icon. The term icon here means threedimensional objects which are visible, concrete embodiments of the myths, beliefs, and values which form a culture's mindset - in short, icon is the tangible shape to invisible ideas (Nachbar \& Lause, 1992, pp. 170-171). This icon has three main characteristics; a) they are all objects, b) express important popular beliefs and values, and c) convey "magical" powers upon their defining group (Nachbar \& Lause, 1992, p. 172). Furthermore, Nachbar \& Lause also divide the icons into six main categories; a) pure personal icons, b) functional personal icons, c) pure local icons, d) functional local icons, e) pure cultural icons, and f) functional cultural icons. This paper will focus more on the last category, functional cultural icons, as they have

[...] an exceedingly complex process (and the movement is not unilateral) but what is important is that we recognize that icons in created environments can help us in understanding the meaning and appeal of both the story form of which they are a part and of the icon's real-life counterpart. Functional cultural icons from television [...] have gained such formal acceptance as important barometers of cultural myths, beliefs, values, and tastes [...] (Nachbar \& Lause, 1992, p. 175)

\section{AMERICAN ICONS IN POPULAR CULTURE}

In particular, this paper will examine a specific cultural icon called 'American icon', which is not just merely an icon, but an icon with underlying American values. Nachbar \& Lause explains that the essential element of American beliefs and values are that of "significant conflict or complexity which runs throughout the history and evolution of the American cultural mindset" (Nachbar \& Lause, 1992, p. 176). Furthermore, Nachbar \& Lause examines the contradiction within the underlying ideals of individual freedom and democracy.

One way to study an American icon, therefore, is to examine the object to determine how it may express this vital conflict between the competing ideals of individual freedom and democracy. (Nachbar \& Lause, 1992, p. 177)

There's a significant disconnection between these two ideas, in which the individual freedom always attributed to the independent movement, power, and identity; while democracy often leads to collective responsibility, stability, citizenship, and majority rule (1992, p. 176). These ideas are what reflected within the socalled American products or American icons; they are democratic because they are mass produced and made equally available for all, and they are also the expression of individual freedom as well, because they are marketed as signs of individual identities. One of the example mentioned in the book is the production of cars. 
In the course of examining cars as an icon balancing individual freedom and democracy, for example, it is quite likely that we will also see that one aspect of that freedom is defined in the American values associated with mobility and discovery, and one aspect of that democracy is expressed in the way cars often bind families together and help maintain vital elements of rural simplicity in modern life. (Nachbar \& Lause, 1992, p. 177)

Upon studying and analyzing the American icons, Nachbar and Lause offer five groups of inquiries to examine the object thoroughly; 1) appearance of the icon, 2) history of the icon, 3) evolutionary change of the icon, 4) iconic group, and 5) exploitation of the icon. The first inquiry is determined solely from the physical appearance of the object - it could be the shape, color, and size. Second inquiry, the object or icon can be examined through how it develops from the very first creation, including the description of what kind of cultural circumstances that helped shape the icon to be significant. These cultural circumstances can be derived from the representation of important values in myths or beliefs. Third, evolutionary change of the icon revolves around the alteration through the year or generation. Nachbar and Lause point out that the more evolving the icon is, then the more it implies the increasing individual freedom values in it. Fourth, the iconic group, is particularly the society that favor the icon. Every object or icon has its own demographic charateristics, whether it's by age, sex, class, region, etc. The last one, exploitation of the icon, basically about the significance of the icon itself; including what makes the icon so appealing to the audience.

The creation of American popular icons is the more visible and concrete form of permeation the aforementioned ideas and values, as they are expressed into artifacts that bind people together by "displaying people's similarities as well as the individual selves". The work of American icons is basically as the anchors which "permit a cuture to float on the shifting currents of change" (Nachbar \& Lause, 1992, p. 178) because it will perpetually be created and produced even in different generations with the same underlying ideas and values.

\section{DISCUSSION}

As the biggest beverage company in the world, Coca-Cola has sold over 3,500 products worldwide in more than 200 countries. In 2012 alone, Coca-Cola company obtained $\$ 9$ billion net profit, and in the same year, Interbrand ranked it as the Most Valuable Company with S77.8 billion value. In terms of advertising and creative marketing, the company also received a lot of recognition. Cannes Lions, the biggest award shows for creativity in communications, awarded the company as Creative Marketer of the Year in 2013 from its various television commercials; "Share a Coke", "Coca-Cola FM Amplifier", "Coca-Cola Share a Can", "Million Reasons to Believe in Thailand", and "Small World Machine". This company truly has a positive track record as it always shows tradition, creativity, and optimism in every of its television advertisement-which also contributes to boost the actual selling numbers of the beverage product.

Jonathan Mildenhall, the Vice President of Coca-Cola's Global Advertising and Content Excellence, explained how this company has been contributing to promote social goods within their marketing strategy-particularly visual communication-since 1970s. Although the commercials are seemingly inspiring and innocent, they were mostly considered provocative in each period which they were 
released. Straddling boundaries and challenging racial prejudice are two of the nine main values of Coca-Cola's advertisements, and this is particularly why they frequently employed multicultural figures within their commercials. Mildenhall further stated that as a powerful company, Coca-Cola has the opportunity and responsibility to create a significant change in the world.

Earlier this year on February 2, 2014, Coca-Cola debuted a teaser of their new television commercial, "America is Beautiful", during the broadcast of America's National Football League biggest tournament, Super Bowl XLVIII. The 60-seconds commercial teaser shows various ethnic groups gather with their relatives or companions, with patriotic song "America the Beautiful" sung in the background with various languages. The commercial was initially made to be broadcasted during Sochi 2014 Olympics, in which Coca-Cola has been taking part as a partner and supporting Olympic Movement since 1928. As it was originally aimed for worldwide audience, seeing the commercial from the perspective of the global citizen shows how the product symbolizes 'togetherness' and breaks the multicultural boundaries. This is the main underlying idea that Coca-Cola in this advertisement is not just an American beverage product, but transforming into an American icon which represents the equality for all, by displaying people with multicultural ethnicities having a great time in America.

\section{COCA-COLA AS AN AMERICAN MULTICULTURAL ICON IN "AMERICA IS BEAUTIFUL"}

The transformation of Coca-Cola into an American icon in this commercial is the process of representation and is explained with the semiotic theory, where the advertisement was seen through two main structures, signifier and signified. The signifiers here were derived from every scene in the "America is Beautiful" advertisement, while the signified meanings were examined through the main five inquiries as described by Nachbar and Lause, and further making a coherence and relevance with the underlying contradictive American values, democracy and individual freedom.

The first step was to see the product through its appearance. The famous countour-shaped CocaCola bottle is designed by The Root Glass Company of Indiana. $^{2}$ It is designed as distinctive as possible to help the product "stand out from other drinks", and that the design is made profoundly to make it "recognizable" even in the dark and when it's already broken. The 'distinctiveness' here is relevant as to the concept of American exceptionalism, a concept that was first brought by puritan John Winthrop in his sermon, "A Model of Christian Charity" in Massachusetts back in 1630. It was the start of the establishment of puritans in the New England, and Winthrop delivered his sermon on a ship, telling his followers that the new place they were going to live in is a "city upon a hill". ${ }^{3}$ Winthrop's preach then had permeated throught he nation, giving the people a new belief that America is the "God's country", as the term "city upon a hill" connotatively means that America is in "the highest position", which later leads to the emergence of American exceptionalism. This idea has been lived up through the generation, for example, during a

2 The Coca-Cola Company, "Who designed the distinctive Coca-Cola bottle?", Coca-Cola Official Website. Accessed from: http://www.coca-cola.co.uk/faq/heritage/whodesigned-the-distinctive-coca-cola-bottle.html

3 John Winthrop, "A Model of Christian Charity". Accessed from: http://religiousfreedom.lib.virginia.edu/sacred/ch arity.html 
speech in Massachusetts, former president John F. Kennedy cited Winthrop's famous metaphor. ${ }^{4}$ Kennedy further elaborates that United States of America have "the eyes of all people" upon them, a country "constructed and inhabited by men aware of their great trust and their great responsibilities".

In relation to the distinctive shape of Coca-Cola, it is clear that the product had wanted to be seen different - or, exceptional — than other products. The "contour bottle" shape, with its ridged glass, bowed middle, and unmistakable curve appeal ${ }^{5}$, is so iconic even in the sillhouette people would recognize that it's Coca-Cola. Before they came up with the idea of this shape, Coca-Cola already had many imitators with the identical names - as Coca-Cola's company historian Phil Mooney explained, there was Cheracola, Dixie Cola, Cocanola - and that the customers weren't too aware about 'which one is the real product'. After the company upgraded the product into the contour shape, Coca-Cola has become so unique and people could identify it easily. The fact that they had 'imitators' it means that Coca-Cola was the pioneer of beverage product that became widely successful. All eyes were on this product, and they saw how it became commercially profitable, thus they deliberately produced the 'imitation' to make profit for themselves as well. In the end, Coca-Cola is still exceptionally

4 John F. Kennedy's address delivered to Joint Convention of General Court of Commonwealth of Massachusetts on January 9, 1961; from the archive of JFK Library. Accessed from: http://www.jfklibrary.org/Asset-

Viewer/OYhUZE2Qo0-ogdV7ok900A.aspx

5 Mark Strassmann, "The real thing: Coke's iconic bottle" (22 July 2012), CBS News. Accessed from: http://www.cbsnews.com/news/the-real-thingcokes-iconic-bottle/ powerful even in its physical form, because people will immediately identify it easily.

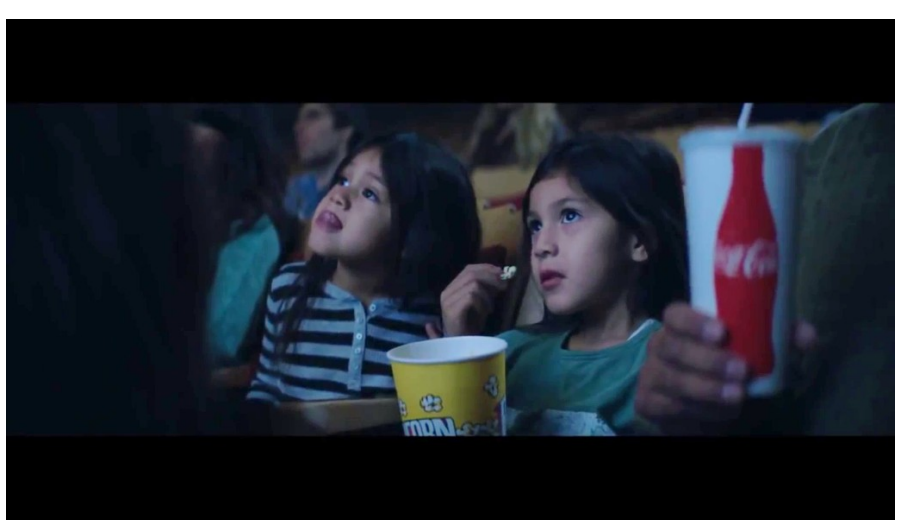

Picture 1. A blurred shape of Coca-Cola stamped in a cork glass

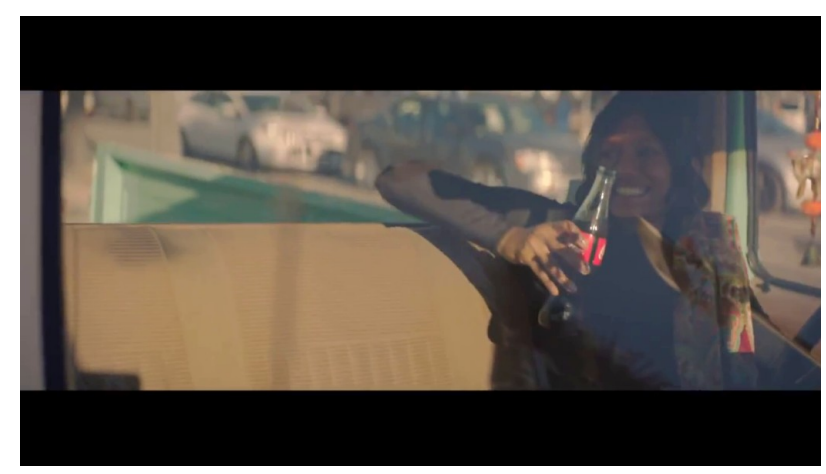

Picture 2. A bottle of Coca-Cola in the woman's hand with the brand label obscured by her hand

From the two images above, which are the screencapped version from the scenes in "America is Beautiful" television advertisment; the product is shown in a not-obvious way. In the first image, there are two little girls enjoying a movie in a cinema, but the person next to them - presumably their relatives - is carrying a large cork glass with the sillhouette of Coca-Cola bottle on it. In the second image, a woman is sitting in her truck, carrying a bottle of CocaCola with her hand obscuring the label. Even when the text of the brand, "Coca-Cola" is nowhere in sight, we need no time to find out 
that they are indeed carrying the product, and that the cork glass is filled with the product. It shows how even the shape alone is already exceptionally remarkable, and recognized worldwide.

The second inquiry requires an explanation about the history of the icon, which in this research is merged with the third inquiry, evolutionary change in the icon, as the two elements are significantly related. "America is Beautiful" is not the first television advertisement from Coca-Cola which depicts multicultural ethnicities in United States. Ever since the company has received worldwide recognition in the 1960s, including the establishment of Coca-Cola in other global places such as Cambodia, Montserrat, Paraguay, Macau, and Turkey ${ }^{6}$; there was a drift in how Coca-Cola made its television advertisement. In the 1970s, Coca-Cola started to make a shift in broadening its international appeal. Still sticking with the idea of reflecting fun, companionship (friends), and enjoying the togetherness (good times), Coca-Cola remarkable embodied the universal joy in 1971 commercial, "I'd Like to Buy the World a Coke". The advertisement showed people with various ethnicities gathered on top of a hill in Italy.

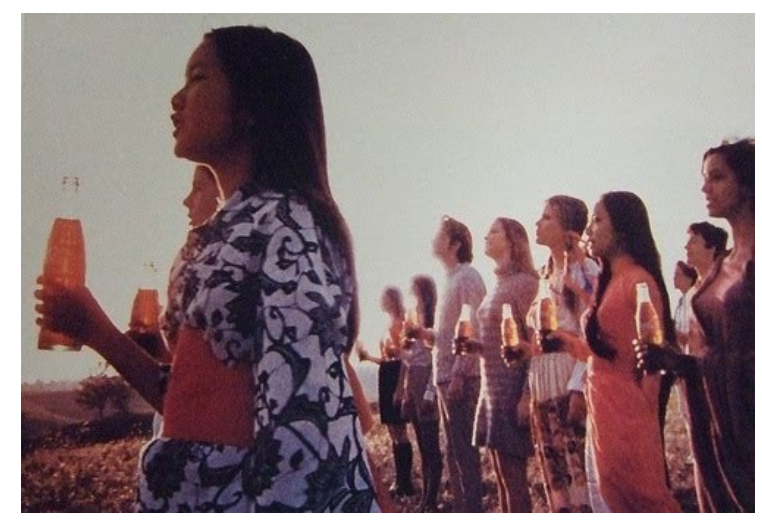

6 The Coca-Cola Company, "The History of Coca-Cola: 1960-1981", Coca-Cola Official Website. Accessed from: http://www.cocacola.co.uk/about-us/history-of-coca-cola-19601981.html

\section{Picture 3. Multicultural figures carrying a bottle of Coca-Cola in "I'd Like to Buy the World a Coke" television advertisement, released in 1971}

Despite not being filmed in United States, this commercial has a similar idea to that of "America is Beautiful". As the very latest campaign of Coca-Cola company in 2014, it has a wide range of 57 years from the aforementioned commercial. And in the 57 years, Coca-Cola has been evolving to a bigger and bigger company internationally, with a more significant codification that it's already an American icon. The shifting of values from Coca-Cola as a beverage that is enjoyed by American people, to the beverage that is enjoyed by international multicultural people, and finally a beverage enjoyed by multicultural people who specifically live in America signify the perpetual evolvement of this popular product. In relevance to Nachbar and Lause's concept of American icon, Coca-Cola wasn't only increased in marketing manner, but the fact that it is now enjoyed by a wider and larger number of people from all around the world, it shows that it was also increased in terms of the fundamental American values, individual freedom and democracy. The product is mass produced (specifically, globally produced) for any kind of people - thus everyone can enjoy it. This also puts a significant element to the fourth inquiry, iconic group or demographic groups, in which Coca-Cola can now be examined in a broader demographic characteristics from all ages, sexes, classes, regions, and ethnicities; with the fact that the company has placed its international offices in more than 200 countries. 


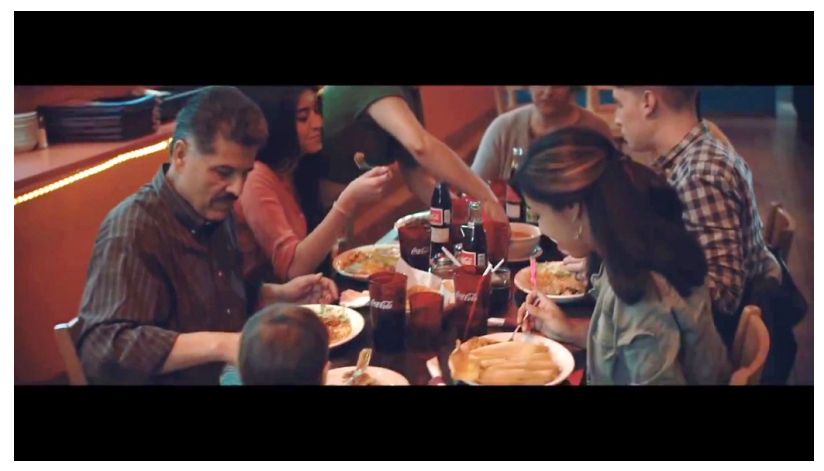

Picture 4. A Mexican family enjoying the meal in a restaurant with Coca-Cola as their main drink.

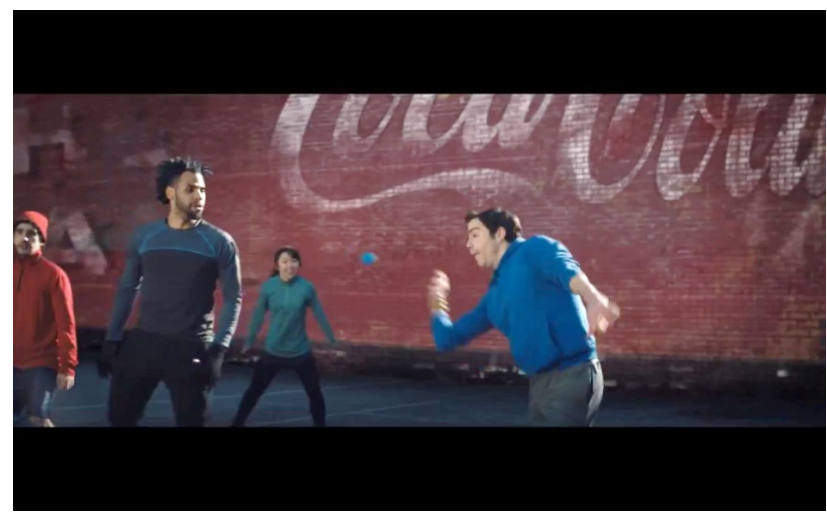

Picture 5. A group of young people with various ethnicities (which features African-American boy, Asian-American girl) playing around in front of a large wall with "Coca-Cola" written on it.

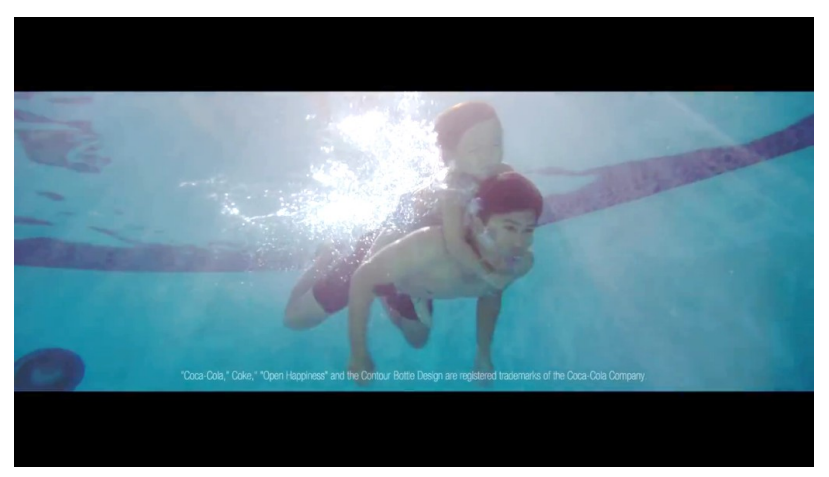

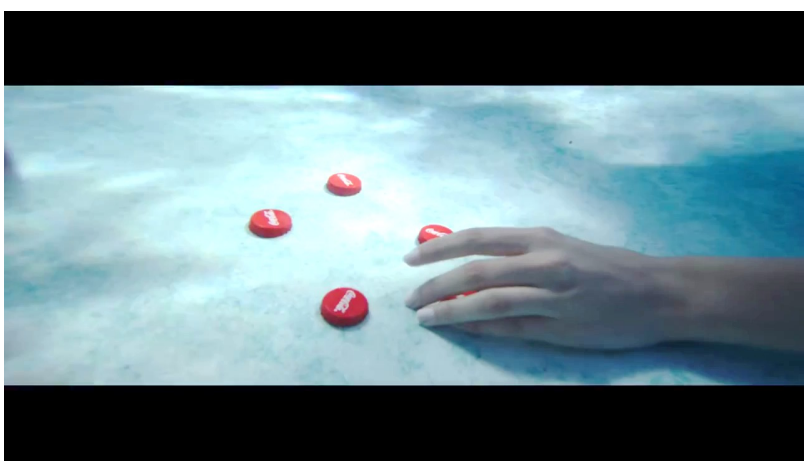

Picture 6-7. A Filipino-American family swimming and plays a game of collecting Coca-Cola bottle caps beneath the pool.

The last inquiry, the exploitation of the icon, is derived from what makes this product so appealing and what is the 'magical power' attached to the icon. From the television advertisement "America Is Beautiful", the magical power is of course how Coca-Cola symbolically binds the people together in their good times, even when it's only featured as a decoration on a wall. Also, the people featured in this advertisement are that of various ethnicities. As aforementioned in the opening of this chapter, 'straddling boundaries and challenging racial prejudice' is one of the key concept in making almost all Coca-Cola advertisement. After its release during Super Bowl, the company released the advertisement internationally on YouTube, in which they announced through their Twitter account with the following introduction: "The only thing more beautiful than this country are the people who live here." As it mentioned "people who

7 Coca-Cola official Twitter account (February 2, 2014), accessed from: https://twitter.com/CocaCola/status/4301408397 63783680 
live here", it indicates that all multicultural figures shown in the commercial are indeed Americans. The commercial tried to live up to the fundamental idea of how America is a multicultural country, just the same as the CocaCola company which has been led by a TurkishAmerican, Muhtar Kent.

Muhtar Kent publicly supports the immigration reform, and wrote an open letter to USA Today on February 23, 2013, titled "Immigration reform good for business". Kent, whose father was a Turkey's consul general for United States when he was born in New York, shared his viewpoints about how immigration is an essential part of the growth calculus for the country. Kent stated how the fortunes of 500 companies in United States were started by immigrants, including the company he's been working for since 1978. Kent took an example of the former Coca-Cola Company CEO, Roberto Goizueta, a Cuban native who's under his leadership; Coca-Cola eventually obtained its top American corporation status by creating vacancies and billions of shareholder value. As the leading country in the world, Kent propelled that United States has the opportunity to promote immigration reform beyond borders, and tried to define the fundamental problem of this reform, which is protectionism. Kent addressed that international organization, such as G-20, United Nations, and World Trade Organization to advance immigration issue in their upcoming summit and meetings.

In his letter, Kent propositioned United States to be more open especially to the immigrants with high competency as they would likely to contribute in the country's economic growth. However, the immigration reform is still required as the current policy is still a restraint for the immigrants. Kent briefly mentioned how immigrants still need to face complicated bureaucracy and 'outdated regulations', and this is one of the main causes why illegal immigrants (or how he wrote it, 'undocumented' immigrants) are prominent in United States. In the other hand, Kent also indirectly encouraged non-US citizens whose dream is to make a living in America. As an immigrant himself, he wrote he was lucky that his family made it easier for him to acquire the American citizenship, but by reforming the immigration policy, Kent was hoping that everyone will have the same chance.

Kent's values are also coherent to the published "values of Coke" by the company in the press release of "America is Beautiful" commercial. According to the press release, the new commercial reinforces the spread of optimism, promotes inclusion, and celebrates humanity. ${ }^{8}$ Katie Bayne, the president of Coca-Cola North America stated, "Our ad provides a snapshot of the real lives of Americans representing diverse ethnicities, religions, races, and families [...] We believe "It's Beautiful" is a great example of the magic that makes our country so special, and a powerful message that spreads optimism, promotes inclusion, and celebrates humanity values that are core to Coca-Cola." These values were also reflected as the commercial used "e pluribus unum" as the title in its online release video on Youtube, which is the Latin phrase included in the Great Seal of United States and also appears on coins and currency. This phrase was also considered as the national motto until 1956. "E pluribus unum" literally means 'out of many, one' but usually rephrased 'one from many', and it refers to the thirteen colonies that joined together to form a single nation of United States. ${ }^{9}$ The meaning, however, evolved through the years, that the unification of United States came from people with various races/ ethnicities, religions, languages, and ancestries..$^{10}$ The latter meaning is more relevant to what "America is Beautiful" attempts to represent, that America is

8 Journey Staff, "America is Beautiful and Coca-Cola is For Everyone" (7 February 2014), Coca-Cola Company official website 
the country where people of the world gather and celebrate.

\section{CONCLUSION}

The emergence of Coca-Cola going global has brought the significance of American company to a whole new level. It has offices in more than 200 countries with global employees, and with the products that already reached out to the most urban areas, that makes Coca-Cola the most popular beverage product in the world-or in another word, a product that can be bought and enjoyed by all kinds of society. This democratic value of Coca-Cola is of course the main reason behind the popularity of the product. Additionally, the company has a remarkably creative marketing team who often trancends Coca-Cola into something else more meaningful than just a beverage product in the advertisements; a symbol, an icon of breaking social boundaries. The company has created numerous creative advertisements all around the world and this year, Coca-Cola came back with a new campaign, "America is Beautiful".

From the displayed image from the scenes along with Nachbar and Lause's five inquiries of American icons, the television advertisement "America is Beautiful" is indeed a representation of Coca-Cola as American multicultural icon. Coca-Cola does contain the contradictive American values of individual freedom and democracy. The advertisement

9 Susan Headley, "E Pluribus Unum - What Does This U.S. Motto Mean?", About.com, accessed from: http://coins.about.com/od/uscoins/f/e_pluribus_u num.htm

10 Edwin Warner, "E Pluribus Unum?" (7 June 1976), TIME Magazine, accessed from: http://content.time.com/time/magazine/article/0, 9171,947739,00.html shows how Coca-Cola can be universally enjoyed by all the people in any occasion which represents the democracy; but at the same time, it shows the multi-ethnic figures that accentuate their role as individuals, thus represents the individual freedom. By showing the multi-ethnic figures in the advertisement, "America is Beautiful", also represents the liberty and equality in America-which is considered beautiful, just like the title - and that the country is the place to celebrate the people of the world.

\section{REFERENCES}

Coca-Cola Company. "Cannes 2013 Winners List". Coca-Cola Company at Cannes 2013. Accessed from: http://thecocacolacompanyatcannes.com/winners-2/

Coca-Cola Company. "Our Company at Glance”. Coca-Cola Company Official Website. Accessed from: http://www.coca-colacompany.com/ourcompany/infographic-coca-cola-at-aglance

Coca-Cola Company. "The History of CocaCola: 1960-1981”, Coca-Cola Official Website. Accessed from: http://www.coca-cola.co.uk/aboutus/history-of-coca-cola-1960-1981.html

Culler, J. 1976. Saussure. London: Fontana

Cultural Politics. Production Analysis. Accessed from:

http://culturalpolitics.net/popular_cultur e/production_analysis

Gallo, Anthony E. "Chapter 9: Food Advertising in the United States" in United States' Department of Agriculture. Economic Research Service. 
Hall, Stuart (ed.). 1997. Representation: Cultural Representations and Signifying Practices. California: Sage Publications.

Headley, Susan. E Pluribus Unum - What Does This U.S. Motto Mean?. About.com. Accessed from: http://coins.about.com/od/uscoins/f/e pl uribus unum.htm

Iezzi, Teressa (ed.). 18 June 2013. The 9 Principles of "Work That Matters". Fast Company. Accessed from: http://www.fastcocreate.com/1683241/th e-9-principles-of-work-that-matters

JFK Library. “John F. Kennedy’s address delivered to Joint Convention of General Court of Commonwealth of Massachusetts on January 9, 1961" Accessed from: http://www.jfklibrary.org/AssetViewer/OYhUZE2Qo0ogdV7ok900A.aspx

Jorney Staff. 7 February 2014. America is Beautiful and Coca-Cola is For Everyone. Coca-Cola Company Official Website.

Kent, Mohtar. 28 February 2013. Immigration reform good for business. USA Today. Accessed from: http://www.usatoday.com/story/opinion/ 2013/02/28/coke-ceo-immigrationreform/1954543/
Nachbar, Jack and Kevin Lause. 1992. Popular Culture: An Introductory Text. Ohio: Bowling Green State University Popular Press

Pope, Daniel. Making Sense of Advertisements. History Matters: The U.S. Survey on the Web.

Accessed from: http://historymatters.gmu.edu

Strassmann, Mark. 22 July 2012. "The real thing: Coke's iconic bottle". CBS News. Accessed from:

http://www.cbsnews.com/news/the-realthing-cokes-iconic-bottle/

Svendsen, Sara Edith. May 2013. Refresh. Create. Inspire: A Rhetorical Analysis of the Mission, Vision and Values Behind The Coca-Cola Company and the Digital Marketing of the "Open Happiness" Campaign. Liberty University

Warner, Edwin. 7 June 1976. E Pluribus Unum?. TIME Magazine. Accessed from: http:/content.time.com/time/magazine/a rticle/0,9171,947739,00.html

Winthrop, John. 1630. "A Model of Christian Charity”. Religious Freedom Library, University of Virginia.

Accessed from: http://religiousfreedom.lib.virginia.edu/s acred/charity.html 
